\title{
Evaluating Factors Influencing Happiness of Preclinical Students
}

\author{
Chantacha Sitticharoon ${ }^{1}$, Nipith Charoenngam ${ }^{2}$, Issarawan Keadkraichaiwat ${ }^{1}$, Pailin Maikaew ${ }^{1} \&$ Vasu \\ Lertsiripatarajit $^{1}$ \\ ${ }^{1}$ Department of Physiology, Faculty of Medicine Siriraj Hospital, Mahidol University, Bangkok, Thailand \\ ${ }^{2}$ Department of Internal medicine, Faculty of Medicine Siriraj Hospital, Mahidol University, Bangkok, Thailand \\ Correspondence: Chantacha Sitticharoon, Department of Physiology, Faculty of Medicine Siriraj Hospital, 2 \\ Wanglang Rd., Siriraj, Bangkok Noi, Bangkok, 10700, Thailand. Tel: 662-419-9721, Fax: 662-411-5009. E-mail: \\ chantacha.sit@mahidol.ac.th
}

Received: December 8, 2021; Accepted: December 29, 2021; Published: December 30, 2021

\begin{abstract}
This study aimed to determine factors influencing happiness in preclinical students especially in aspects of teaching and learning, students' motivation, study habits, and academic achievement. This study was a questionnaire-based cross-sectional study. The questionnaire was validated and approved for clarity, readability, rational analysis, and comprehensiveness by the experts. Questionnaires were sent to all second and/or third-year medical students of the 2018 (328) and 2019 (329) classes, Faculty of Medicine Siriraj Hospital, Mahidol University, Thailand. Cronbach's alpha values were 0.886 . The data were analyzed by the Statistical Package for Social Science version 18. From open-ended questions, the top 5 ranking factors increasing students' happiness were teaching of instructors, content satisfaction, content understanding, free time, and handouts. Factors that had positive influences/associations with happiness of preclinical students were happiness in learning subjects taught in a particular year; satisfaction of content, study outcomes, materials, handouts, teaching motivating desire to learn, and applicability of content to medical profession; high motivation to study medicine, expected score, and the percentage of achievement of study targets; less amount of time spent on recorded-e-lecture study and internet for non-academic use; and low stress. Happiness of preclinical students was influenced by satisfaction in teaching and learning, their attitude, study habits, and academic achievement. Further studies on determining students' happiness after improvement of teaching and learning environments, augmenting activities that enhance students' motivation, and promoting good study habits among medical students, are required to prove whether enhancement of these factors could effectively increase students' happiness.
\end{abstract}

Keyword: preclinic, happiness, academic achievement, teaching, learning

\section{Introduction}

Preclinical medical students have complained that they had less happiness and higher stress levels during preclinical years compared to premedical year because of new environments, loads of content, and new medical terminology. Learning in preclinical years is thought to be tough and stressful (Aktekin, Karaman, Senol, Erdem, Erengin, \& Akaydin, 2001; Rahman, Ismali, Seman, Rosli, Jusoh, Dali, Islam, \& Haque, 2013) as students need to adjust themselves to new academic environments, new subjects, unfamiliar medical terms, heavy academic loads, failure to achieve study targets, and examination (Rahman et al., 2013; Saipanish, 2003). Patience and commitment are needed for preclinical students to effectively learn and understand the content. All of these lead to the fact that medical students have higher stress levels than students in other areas (Aktekin et al, 2001; Eva, Islam, Mosaddek, Rahman, Rozario, Iftekhar, Ahmed, Jahan, Abubakar, Dali, Razzaque, Habib, \& Haque, 2015), resulting in decreased happiness (Kjeldstadli, Tyssen, Finset, Hem, Gude, Gronvold, Ekeberg, \& Vaglum, 2006). A meta-analysis study showed that the prevalence of depression or depressive symptoms was $27.2 \%$ among medical students and limited evidences suggested that some specific interventions regarding learning environment were associated with improved emotional well-being among medical students (Slavin, 2016).

Happiness of students was reported to have positive associations with academic achievement, exercise, young age, engagement, reported high/middle income, emotional intelligence (Alshehri, Althobaiti, Alsaadi, Alnemari, Alyami, Alyami, \& Alswat, 2016), mental health (Sasanpour, Khodabakhshi, \& Nooryan, 2012), marital status, and living with family (Sahraian \& Vakili, 2012); and a negative association with depression (Bahrami, Rajaeepour, Rizi, Zahmatkesh, \& Nematolahi, 2011). A study in medical students found that predictors of higher happiness were family relationship, grade point average (GPA) at 2.51-3.00 (compared to 2.01-2.50), satisfaction in own 
physical health, self-desire to study medicine, and prior perception) of medical students' life style (Wongratanacheewin, Vimonvanich, Teeratakulpisarn, Srimanta, Pooparadorn, Choorus, Chitkulsampan, Paileeklee, \& Srisaenpang, 2015).

Most previous studies reported associations between happiness of students and general lifestyle factors, but only few studies reported its association with factors in aspects of teaching and learning. Apart from the previous studies, our study highlights the influence of teaching and learning as well as students' motivation and study habits. This study was conducted in 2 classes of students to determine trends of the results in different classes. In one class, the study was performed in 2 preclinical years, the 1st preclinical year (Preclinic1) and the 2nd preclinical year (Preclinic2). This study aimed to 1) determine factors that increase happiness in preclinical medical students; 2) compare levels of happiness in preclinical medical students among different groups of students according to their motivation to study medicine, study habits, stress levels, and academic achievement; 3) compare their study habits among different groups of students' happiness score; and 4) determine correlations/interactions of happiness with other factors including teaching and learning factors, students' motivation, study habits, and academic achievement Revelation of factors affecting happiness would be beneficial for academic management of course planning to promote factors that increase students' happiness as well as to advise students to accommodate themselves to be happier. Furthermore, such factors might be used for monitoring wellbeing and levels of happiness in medical students throughout the academic year.

\section{Methods}

\subsection{Subjects}

Subjects of this study were medical students in the second and/or the third year of 2018 and 2019 classes, Faculty of Medicine Siriraj Hospital, Mahidol University, Thailand.

\subsection{The Questionnaire}

This study was a questionnaire-based cross-sectional study. The self-report questionnaire written in Thai had 4 sections including 1) open-ended questions, 2) box-ticking, 3) happiness scale marking, and 4) satisfaction score rating of various aspects in teaching and learning. The questionnaire was firstly reviewed by medical students to affirm its readability and clarity. This questionnaire was then submitted, assessed, validated, and approved for clarity, readability, rational analysis, and comprehensiveness by the experts.

The open-ended questions had 4 items including 1$)$ demographic data which were body weight $(\mathrm{kg})$ and height (cm); 2$) 3$ factors that increased their happiness; 3) study habits which were time spent on academic/non-academic internet use (hours/day), time spent on lesson review by non-recorded-e-lecture/recorded-e-lecture study (hours/week), the examination expectation score in the percentage (\%), the percentage of achievement of study targets (\%), and the percentage of lesson review by recorded-e-lecture study per class (\%); and 4) students' behaviors which were time spent on exercise and extracurricular activities (hours/week), numbers of days having breakfast (days/week), time (s) of party (time (s)/month), wake up time and sleep time (o'clock), and duration of sleep (hours/night). Recorded-e-lecture is defined as the record of lecture took place in a certain class which was uploaded on the intranet and could be accessed by students anytime after the class. The percentage of time spent on recorded-e-lecture study per class is obtained by the proportion of time spent on recorded-e-lecture study divided by total time of the class. The examination expectation score in the percentage was defined as the prediction of the score that students expected to get in the percentage. The percentage of achievement of study targets was obtained from the percentage of the content that students achieved in relation to the total content they intended to study.

The box-ticking questions had 2 items including 1) motivation to study medicine (low, medium, and high) and 2) stress levels $(1=$ very low, $2=$ low, $3=$ medium, $4=$ high, $5=$ very high $)$.

Happiness/unhappiness scale was obtained from the Fordyce emotion questionnaire (Rabito-Alcon \& RodriguezMolina, 2016), ranging from 0 of the extremely unhappy to 10 of the extremely happy score. Students were asked to provide the score of their happiness on 2 occasions including 1) at the current and the previous years, and 2) their happiness of the subjects taught in a certain academic year. Students of the 2019 class were asked to provide the happiness score of the premedical year and Preclinic1 when they were in Preclinic1; and of Preclinic 2 when they were in Preclinic2. Students of the 2018 class were asked to provide the happiness score of the premedical year, Preclinic1, and Preclinic2 when they were in Preclinic2. Subjects in the questionnaire included physiology, gross anatomy, histology, embryology, and biochemistry for Preclinic1; and pharmacology, microbiology, pathology, clinical pathology, immunology, and parasitology for Preclinic2. Satisfaction scores in teaching and 
learning aspects were also obtained from the same scale of happiness, including satisfaction in content, learning outcomes, materials, handouts, teaching motivating desire to learn, applicability of content, and evaluation.

Questionnaires were sent to all second and/or third-year medical students of the 2018 and 2019 classes. For students of the 2018 class, the questionnaires were sent to all 328 medical students when they were studying at the end of Preclinic2 (2018/2) with 274 (83.54\%) being returned. For students of the 2019 class, the questionnaires were sent to all 329 medical students when they were studying at the end of Preclinic1 (2019/1) and Preclinic2 (2019/2), with $280(85.11 \%)$ and $284(86.32 \%)$ being returned, respectively. Cronbach's alpha values, used to determine the internal consistency (reliability) of data collection, were 0.886 .

\subsection{Academic Achievement and Class Attendance}

Academic achievement, including scores of subjects taught in a certain academic year, GPA, cumulative GPA (cGPA), and the comprehensive examination score; and class attendance including instance (s) of lateness to class and absence from class per academic year and check-in time were obtained from the undergraduate education department.

\subsection{Subgroup Analysis}

We determined levels of happiness of students of a certain academic year compared between groups of students, based on potential happiness determinants including academic year, motivation to study medicine, stress levels, body mass index (BMI), and quartiles of time spent on internet for non-academic use $(<2,2-<3,3-<5$, and $\geq 5$ hours/day). We also determined students' academic achievement (GPA), attitude, and study habits according to different levels of the happiness score of students, including score of $\leq 2.5$ classified as very low happiness, $>2.5-$ 5 classified as low happiness, $>5-7.5$ classified as high happiness, and $>7.5-10$ classified as very high happiness.

\subsection{Statistical Analysis}

The data were analyzed by the Statistical Package for Social Science version 18. Factors increasing happiness were reported as the percentage of students who ranked that factor as the first order. The Kolmogorov-Smirnov test was performed to test normality of the data. The one-way analysis of variance (ANOVA) were used to compare data with more than 2 groups followed by Post-hoc analyses, using the Fisher's least significant difference test where appropriate. Correlations between 2 factors were determined by the Pearson product-moment correlation coefficient. Multiple linear regression analysis was used to test which factors (all numerical, nominal, and ordinal variables) had a significant contribution to happiness of students in each academic year. For non-normal distributed and ordinal variables, the non-parametric test was used. The $P$ value of $<0.05$ is considered statistically significant.

\section{Results}

\subsection{Factors Increasing Happiness of Students}

The top ten ranks of factors increasing happiness of the 2019/1, 2019/2, and 2018/2 students were shown in the percentage of students who answered that particular factor increased their happiness in Table 1.

Table 1. Factors increasing happiness of the students of the 2019 class in the first (2019/1) and the second (2019/2) preclinical years and the students of the 2018 class of the second preclinical years $(2018 / 2)$.

\begin{tabular}{|r|l|r|}
\hline \multicolumn{2}{|l|}{$\mathbf{2 0 1 9 / 1}$} & \\
\hline Order & Factors & $\%$ \\
\hline 1 & Teaching of instructor & 16.43 \\
\hline 2 & Content satisfaction & 16.43 \\
\hline 3 & Content understanding & 10.36 \\
\hline 4 & Handout & 10.36 \\
\hline 5 & Free time & 9.64 \\
\hline 6 & Having friends & 7.14 \\
\hline 7 & Extracurricular activities & 5.36 \\
\hline 8 & Sleep & 4.29 \\
\hline 9 & Applicability of content to medical profession & 3.93 \\
\hline 10 & Academic achievement & 3.21 \\
\hline
\end{tabular}




\begin{tabular}{|r|l|c|}
\hline \multicolumn{2}{|l|}{$\mathbf{2 0 1 9 / 2}$} & \\
\hline Order & Factors & $\mathbf{\%}$ \\
\hline 1 & Free time & 17.53 \\
\hline 2 & Content satisfaction & 16.23 \\
\hline 3 & Teaching of instructors & 13.63 \\
\hline 4 & Content understanding & 13.31 \\
\hline 5 & Applicability of content to medical profession & 4.54 \\
\hline 6 & Handout & 4.22 \\
\hline 7 & Sleep & 3.89 \\
\hline 8 & Learning satisfaction & 3.57 \\
\hline 9 & Having friends & 2.59 \\
\hline 10 & Extracurricular activities & 2.59 \\
\hline $\mathbf{2 0 1 8} \mathbf{2}$ & \multicolumn{1}{|c|}{} \\
\hline Order & Factors & $\%$ \\
\hline 1 & Teaching of instructor & 18.11 \\
\hline 2 & Content satisfaction & 16.23 \\
\hline 3 & Content understanding & 12.83 \\
\hline 4 & Handout & 12.08 \\
\hline 5 & Having friends & 7.17 \\
\hline 6 & Free time & 6.79 \\
\hline 7 & Sleep & 5.28 \\
\hline 8 & Applicability of content to medical profession & 4.91 \\
\hline 9 & Academic achievement & 3.02 \\
\hline 10 & Extracurricular activities & 3.02 \\
\hline \multicolumn{2}{|l}{}
\end{tabular}

Data are shown as the percentage of students who answered that particular factor increased their happiness. 3.2 Comparisons of Happiness between Groups of Students Based on Academic Year, Motivation to Study Medicine, Stress Levels, BMI, and Quartiles of Time Spent on Internet for Non-Academic Use

Happiness of the students of the 2018 and 2019 classes was highest when they were in the premedical year, which was significantly higher than theirs in Preclinic1 and Preclinic2 $(\mathrm{p}<0.001$ all) (Figure 1A). Their happiness in Preclinic1 was comparable to Preclinic2 in both classes (Figure1A). In students of the 2019 class when they were in the premedical year, happiness of those with high and moderate motivation to study medicine was significantly higher than those with low motivation, ( $\mathrm{p}<0.05$ all) (Figure 1B). However, happiness score was comparable among groups of different motivation of the students of the 2018 class when they were in the premedical year (Figure 1C). In both classes, happiness was highest in the students with high motivation which was significantly higher than those with medium and low motivation; and was significantly higher in the students with medium motivation than those with low motivation in both Preclinic1 and Preclinic2, ( $<0.05$ all) (Figure 1B\&1C). The students in both classes with high and extremely high stress levels had lower happiness than those with moderate, low, and extremely low stress levels (Figure 1D). Happiness was comparable between groups of BMI in the 2019/1, 2019/2, and 2018/2 classes (Figure 1E). For time spent on internet for non-academic use, happiness of the 2019/2 students who had such factor of $<2$ hours/week tended to be higher than those who had such factor of $3-<5$ hours/week ( $\mathrm{P}=0.073$ ); and happiness of the $2018 / 2$ students who had such factor of $<2$ hours/week and $2-<3$ hours/week was significantly higher than those who had such factor of $3-<5$ and $\geq 5$ hours/week ( $p<0.05$ all) (Figure 1F).
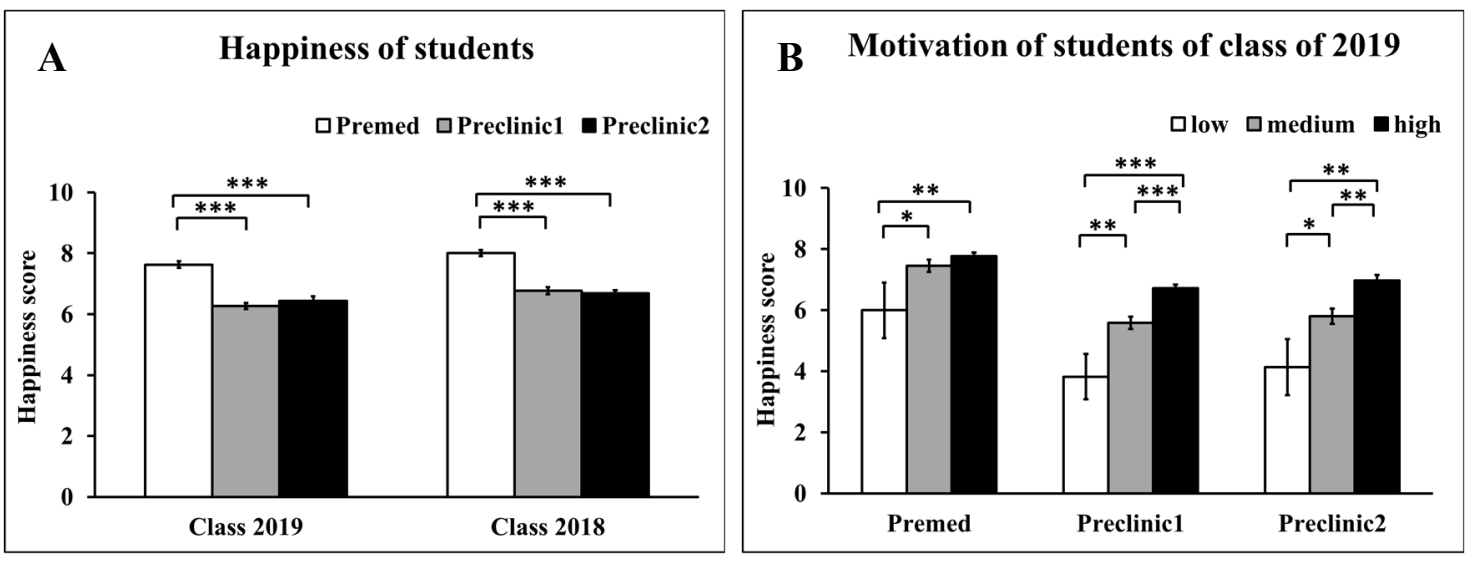

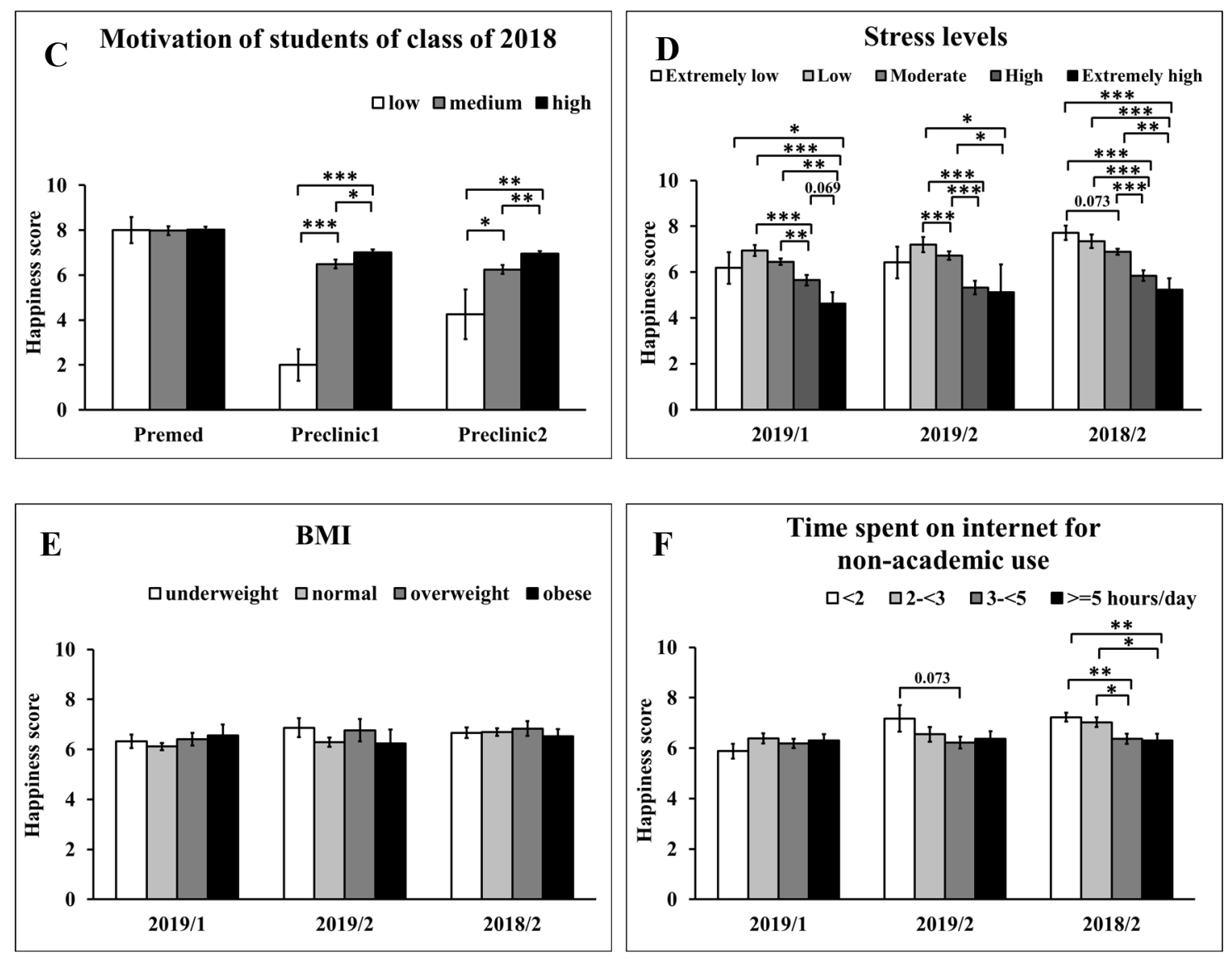

Figure 1. Comparisons of happiness between groups of students based on academic year (A), motivation to study medicine of the students of the 2019 (B) and 2018 (C) classes, stress levels (D), body mass index (BMI) (E), and quartiles of time spent on internet for non-academic use (F). Premed represents the premedical year, Preclinic1 and Preclinic2 represent the first and second preclinical years, respectively. 2019/1 and 2019/2 represent the students of the 2019 class in the first and second preclinical years, respectively. 2018/2 represents the students of the 2018 class in the second preclinical year.

Data are shown as mean ( \pm S.E.M.), $* \mathrm{p}<0.05 * * \mathrm{p}<0.01, * * * \mathrm{p}<0.001$ compared between groups

\subsection{Comparisons of Students' GPA, Attitude, and Study Habits between Groups of Different Happiness Scores}

The 2018/2 students with very high happiness had significantly higher GPA than those with very low, low, and high happiness $(\mathrm{P}<0.05$ all); and those with high happiness had significantly higher GPA than those with very low happiness $(\mathrm{P}<0.05)$ (Figure $2 \mathrm{~A})$.

The 2019/1 students who had very high happiness had significantly higher expected score than those who had very low, low, and high happiness $(\mathrm{P}<0.05$ all); and those who had high happiness had significantly higher expected score than those who had very low happiness $(\mathrm{P}<0.05)$ (Figure $2 \mathrm{~B})$. The $2018 / 2$ students with very high happiness had significantly higher expected score than those with low and high happiness $(\mathrm{P}<0.05$ all $)$ (Figure $2 \mathrm{~B})$.

For study habits, the percentage of achievement of study targets was significantly higher in the 2019/1 students with very high happiness compared to those with very low, low, and high happiness $(\mathrm{P}<0.05$ all $)$; and was significantly higher in those with high happiness compared to those with very low and low happiness $(\mathrm{P}<0.01$ all $)$ (Figure 2C). Such factor in the 2018/2 students was significantly higher in those with very high happiness compared to those with very low and low happiness $(\mathrm{P}<0.01$ all $)$; and was significantly higher in those with high happiness compared to those with very low happiness $(\mathrm{P}<0.05)$ (Figure $2 \mathrm{C})$.

The 2019/2 students with very low happiness had significantly higher time spent on lesson review than those with low, high, and very high happiness $(\mathrm{P}<0.05$ all) (Figure 2D). The 2019/1 students with very low happiness had significantly lower time spent on non-recorded-e-lecture study compared to those with high and very high 
happiness ( $\mathrm{P}<0.05$ all) (Figure 2E). The 2019/2 students with very low happiness had significantly higher time spent on recorded-e-lecture study compared to those with low, high, and very high happiness $(\mathrm{P}<0.05$ all) (Figure 2F). For time spent on exercise, the 2019/1 students with very high happiness tended to have higher time spent on exercise than those with low happiness $(\mathrm{P}=0.075)$ (Figure 2G).

The 2019/1 students with very low happiness had significantly higher instances of lateness to class and absence from class than those with high and very high happiness $(\mathrm{P}<0.05$ all $)$ and tended to have higher such factor than those with low happiness $(\mathrm{P}=0.069)$ (Figure $2 \mathrm{H})$. The $2019 / 2$ students with very low and low happiness had significantly higher such factor than those with high happiness ( $\mathrm{P}<0.05$ all) (Figure 2H). Furthermore, the 2018/2 students with very low happiness had significant higher instances of lateness to class and absence from class than those with low, high, and very high happiness $(\mathrm{P}<0.01$ all) (Figure $2 \mathrm{H})$.
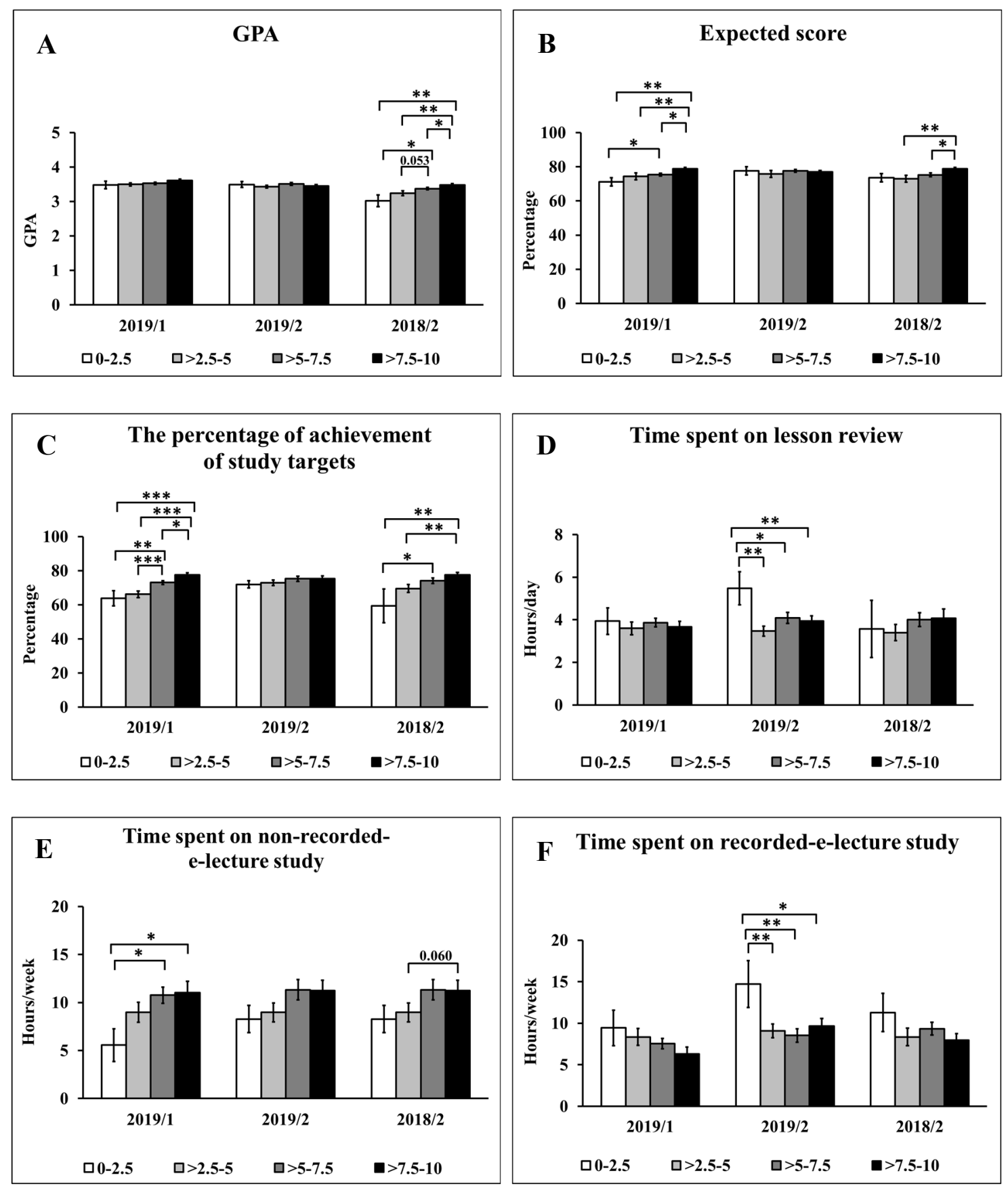

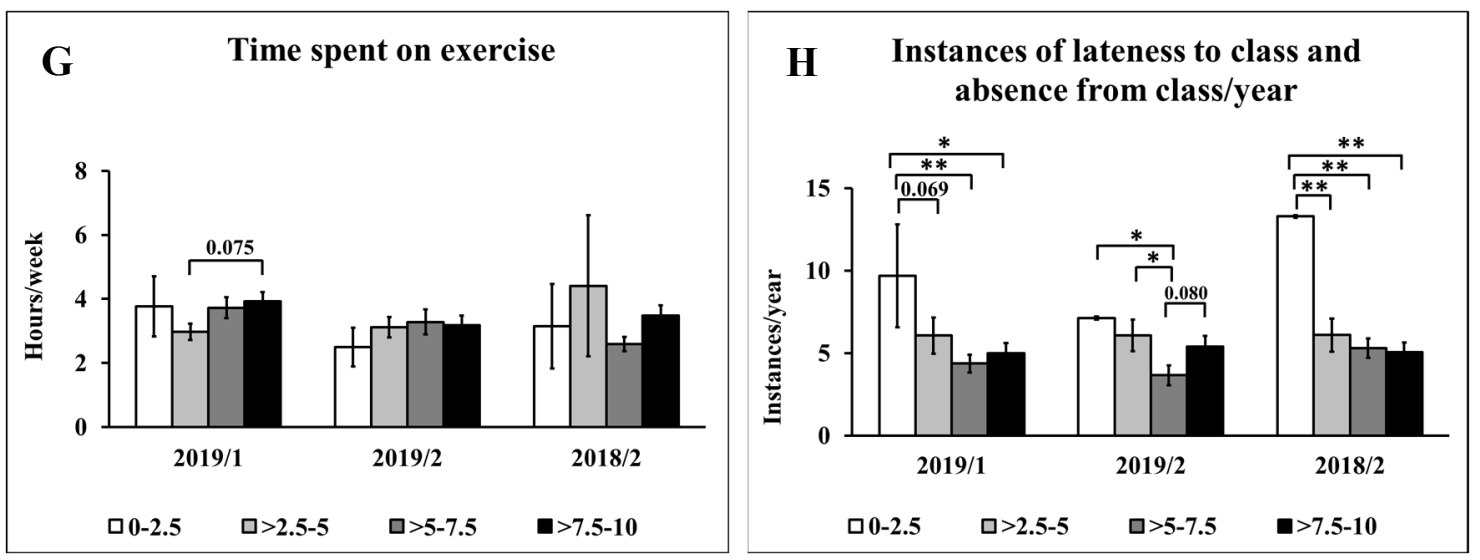

Figure 2. Comparisons of students' GPA, attitude, and study habits between groups of different happiness scores, including 0-2.5 (very low), >2.5-5 (low), >5-7.5 (high), and >7.5-10 (very high) groups in aspects of GPA (A), the examination expectation score in the percentage (expected score) (B), the percentage of achievement of study targets (C), time spent on lesson review (D), time spent on non-recorded-e-lecture study (E), time spent on recorded-e-lecture study $(\mathrm{F})$, time spent on exercise $(\mathrm{G})$, and instances of lateness to class and absence from class/year (H). 2019/1 and 2019/2 represent the students of the 2019 class in the first and second preclinical years, respectively. 2018/2 represents the students of the 2018 class in the second preclinical year.

Data are shown as mean $\left( \pm\right.$ S.E.M.), ${ }^{*} \mathrm{p}<0.05,{ }^{* *} \mathrm{p}<0.01,{ }^{* *} \mathrm{p}<0.001$ compared between groups

\subsection{Correlations between 2 Factors}

Correlations between happiness of the 2019/1, 2019/2, and 2018/2 students with other factors are shown in Table 2. Happiness of the 2019/1 students had significantly positive correlations with motivation to study medicine; happiness in learning gross anatomy, physiology, biochemistry, histology, and embryology; satisfaction of content, study outcomes, materials, handouts, teaching motivating desire to learn, and applicability of content to medical profession; expected score; the percentage of achievement of study targets; time spent on non-recorded-e-lecture study; scores of gross anatomy 1, gross anatomy 2, histology, embryology, neuroanatomy, biochemistry, and physiology; and GPA in Preclinic1 but had significantly negative correlations with the percentage of time spent on recorded-e-lecture study/class and stress levels ( $\mathrm{P}<0.05$ all) (Table 2$)$.

Happiness of the 2019/2 students was significantly positively correlated with motivation to study medicine; happiness of students in Preclinic1; happiness in learning pathology, clinical pathology, parasitology, microbiology, pharmacology, and immunology; satisfaction of content, study outcomes, materials, handouts, applicability of content to medical profession, teaching motivating desire to learn, and evaluation; the percentage of achievement of study targets; and number of days having breakfast/week but was significantly negatively correlated with cGPA and stress levels $(\mathrm{P}<0.05$ all) (Table 2$)$.

Happiness of the 2018/2 students was significantly positively correlated with motivation to study medicine; happiness of students in Preclinic1; happiness in learning pathology, clinical pathology, parasitology, microbiology, pharmacology, and immunology; satisfaction of content, study outcomes, materials, handouts, expected scores, applicability of content to medical profession, and teaching motivating desire to learn; the percentage of achievement of study targets; evaluation satisfaction; scores of clinical pathology, microbiology, pathology 1, pathology 2, pharmacology, parasitology, preventive medicine, and pathophysiology; GPA in preclinic2; cGPA; the comprehensive score; and number of days having breakfast/week but was significantly negatively correlated with the percentage of time spent on recorded-e-lecture study/class; stress levels; instances of lateness to class and absence from class /year; and sleep time ( $\mathrm{P}<0.05$ all) (Table 2). 
Table 2. Correlations between happiness of students of the $\mathbf{2 0 1 9}$ class in the first (2019/1) and the second (2019/2) preclinical years and of the 2018 class in the second preclinical year $\mathbf{( 2 0 1 8 / 2 )}$ with other factors

\begin{tabular}{|c|c|c|c|c|}
\hline Happiness of 2019/1 students & \multicolumn{2}{|c|}{ Happiness of students } & \multirow{2}{*}{$\begin{array}{l}\text { 2019/2 } \\
\text { R }\end{array}$} & \multirow{2}{*}{$\begin{array}{l}\text { 2018/2 } \\
R\end{array}$} \\
\hline Factors & $\mathbf{R}$ & Factors & & \\
\hline - Motivation to study medicine & $0.38 * * *$ & - Motivation to study medicine & $0.27 * * *$ & $0.24 * * *$ \\
\hline - Gross anatomy happiness & $0.47 * * *$ & - Happiness of students in Preclinic1 & $0.61 * * *$ & $0.20 * *$ \\
\hline - Physiology happiness & $0.50 * * *$ & - Pathology happiness & $0.24 * * *$ & $0.35 * * *$ \\
\hline - Biochemistry happiness & $0.40 * * *$ & - Clinical pathology happiness & $0.23 * * *$ & $0.16^{* *}$ \\
\hline - Histology happiness & $0.39 * * *$ & - Parasitology happiness & $0.18 * *$ & $0.20 * *$ \\
\hline - Embryology happiness & $0.25 * * *$ & - Microbiology happiness & $0.19 * *$ & $0.47 * * *$ \\
\hline - Content satisfaction & $0.31 * * *$ & - Pharmacology happiness & $0.26 * * *$ & $0.33 * * *$ \\
\hline - Satisfaction of study outcomes & $0.27 * * *$ & - Immunology happiness & $0.15 *$ & $0.36 * * *$ \\
\hline - Material satisfaction & $0.17 * *$ & - Content satisfaction & $0.31 * * *$ & $0.37 * * *$ \\
\hline - Handout satisfaction & $0.15^{*}$ & - Satisfaction of study outcomes & $0.31 * * *$ & $0.43 * * *$ \\
\hline $\begin{array}{l}\text { - Satisfaction of teaching } \\
\text { motivating desire to learn }\end{array}$ & $0.26 * * *$ & - Material satisfaction & $0.28 * * *$ & $0.26^{* * *}$ \\
\hline $\begin{array}{l}\text { - Satisfaction of applicability of } \\
\text { content to medical profession }\end{array}$ & $0.22 * * *$ & - Handout satisfaction & $0.22 * * *$ & $0.24 * * *$ \\
\hline - Expected score & $0.20 * *$ & - Expected score & 0.03 & $0.21 * * *$ \\
\hline $\begin{array}{l}\text { - Percentage of achievement of } \\
\text { study targets }\end{array}$ & $0.28 * * *$ & $\begin{array}{l}\text { - Satisfaction of applicability of } \\
\text { content to medical profession }\end{array}$ & $0.15^{*}$ & $0.16^{*}$ \\
\hline $\begin{array}{l}\text { - Time spent on non-recorded-e- } \\
\text { lecture study (hours/week) }\end{array}$ & $0.14^{*}$ & $\begin{array}{l}\text { - Satisfaction of teaching motivating } \\
\text { desire to learn }\end{array}$ & $0.32 * * *$ & $0.37 * * *$ \\
\hline - Gross Anatomy 1 score & $0.12^{*}$ & $\begin{array}{l}\text { - Percentage of achievement of study } \\
\text { targets }\end{array}$ & $0.14 *$ & $0.26^{* * *}$ \\
\hline - Gross Anatomy 2 score & $0.18 * *$ & - Evaluation satisfaction & $0.15 * *$ & $0.22 * * *$ \\
\hline - Histology score & $0.16 * *$ & - Clinical pathology score & -0.02 & $0.19 * *$ \\
\hline - Embryology score & $0.17 * *$ & - Microbiology score & -0.02 & $0.25 * * *$ \\
\hline - Neuroanatomy score & $0.16 * *$ & - Pathology 1 score & -0.02 & $0.24 * * *$ \\
\hline - Biochemistry score & $0.15^{*}$ & - Pathology 2 score & 0.04 & $0.23 * * *$ \\
\hline - Physiology score & $0.14^{*}$ & - Pharmacology score & 0.02 & $0.25 * * *$ \\
\hline - GPA Preclinic1 & $0.13 *$ & - Parasitology score & -0.04 & $0.16^{*}$ \\
\hline $\begin{array}{l}\text { - Percentage of time spent on } \\
\text { recorded-e-lecture study/class }\end{array}$ & $-0.21 * * *$ & - Preventive medicine score & -0.04 & $0.14 *$ \\
\hline - Stress & $-0.27 * * *$ & - Pathophysiology score & -0.04 & $0.19 * *$ \\
\hline & & - GPA Preclinic2 & -0.01 & $0.24 * * *$ \\
\hline & & - cGPA & $-0.16 * *$ & $0.13 *$ \\
\hline & & - Comprehensive score & 0.02 & $0.25 * * *$ \\
\hline & & $\begin{array}{l}\text { - Number of days having } \\
\text { breakfast/week }\end{array}$ & $0.15^{*}$ & $0.13 *$ \\
\hline & & $\begin{array}{l}\text { - Percentage of time spent on } \\
\text { recorded-e-lecture study/class }\end{array}$ & -0.09 & $-0.13 *$ \\
\hline & & - Stress levels & $-0.23 * * *$ & $-0.35 * * *$ \\
\hline & & $\begin{array}{l}\text { - Instances of lateness to class and } \\
\text { absence from class/year }\end{array}$ & -0.06 & $-0.13 *$ \\
\hline & & - Sleep time (o'clock) & -0.04 & $-0.14^{*}$ \\
\hline
\end{tabular}

$* \mathrm{p}<0.05, * * \mathrm{p}<0.01, * * * \mathrm{p}<0.001$

\subsection{Multivariate Regression Analysis}

Taking happiness of the 2019/1 students as a dependent variable, 5 models of significant interactions were found when setting motivation to study medicine $(\mathrm{R}=0.419)$ (model 1$)$; or motivation to study medicine and stress levels $(\mathrm{R}=0.487)$ (model 2); or motivation to study medicine, stress levels, and content satisfaction $(\mathrm{R}=0.531)($ model 3); or motivation to study medicine, stress levels, content satisfaction, and the percentage of achievement of study targets $(\mathrm{R}=0.560)$ (model 4); or motivation to study medicine, stress levels, content satisfaction, the percentage of 
achievement of study targets, and times of party per month $(\mathrm{R}=0.567)$ (model 5) as independent variables $(\mathrm{P}<0.001$ all) (Table 3).

By setting happiness of the 2019/2 students as a dependent variable, 4 models of significant interactions were observed by using motivation to study medicine $(\mathrm{R}=0.306)$ (model 1); or motivation to study medicine and satisfaction of teaching motivating desire to learn ( $\mathrm{R}=0.363)$ (model 2); or motivation to study medicine, satisfaction of teaching motivating desire to learn, and time spent on extracurricular activities (hours/week) $(\mathrm{R}=0.402)$ (model 3); or motivation to study medicine, satisfaction of teaching motivating desire to learn, time spent on extracurricular activities (hours/week), and stress levels $(\mathrm{R}=0.429)$ (model 4) as independent variables $(\mathrm{P}<0.001$ all) (Table 3).

By setting happiness of the 2018/2 students as a dependent variable, 5 models of significant interactions were observed by using satisfaction of study outcomes $(\mathrm{R}=0.447)$ (model 1$)$; or satisfaction of study outcomes and stress levels $(\mathrm{R}=0.521$ ) (model 2); or satisfaction of study outcomes, stress levels, and motivation to study medicine $(\mathrm{R}=0.545)$ (model 3); or satisfaction of study outcomes, stress levels, motivation to study medicine, and sleep time $(\mathrm{R}=0.560)$ (model 4); satisfaction of study outcomes, stress levels, motivation to study medicine, sleep time, and number of days having breakfast/week $(\mathrm{R}=0.557)$ (model 5) as independent variables $(\mathrm{P}<0.001$ all $)$ (Table 3$)$.

Table 3. Multivariate regression analysis of happiness of students

\begin{tabular}{|c|c|c|c|c|c|c|c|c|}
\hline $\begin{array}{l}\text { M } \\
\text { o } \\
\text { d } \\
\text { e } \\
\text { l }\end{array}$ & $\mathbf{R}$ & $\mathbf{R}^{2}$ & P value & & $\begin{array}{l}\text { Coef- } \\
\text { ficient }\end{array}$ & $\begin{array}{l}\text { Standard } \\
\text { error }\end{array}$ & T value & $\begin{array}{l}P \\
\text { value }\end{array}$ \\
\hline \multicolumn{9}{|c|}{ Students of the 2019 class in the first preclinical year } \\
\hline \multirow{2}{*}{1} & \multirow{2}{*}{0.419} & \multirow{2}{*}{0.176} & \multirow{2}{*}{$<0.001 * * *$} & (Constant) & 2.636 & 0.479 & 5.504 & $<0.001 * * *$ \\
\hline & & & & Motivation to study medicine & 1.389 & 0.181 & 7.660 & $<0.001 * * *$ \\
\hline \multirow{3}{*}{2} & \multirow{3}{*}{0.487} & \multirow{3}{*}{0.237} & \multirow{3}{*}{$<0.001 * * *$} & (Constant) & 4.374 & 0.590 & 7.409 & $<0.001 * * *$ \\
\hline & & & & Motivation to study medicine & 1.342 & 0.175 & 7.671 & $<0.001 * * *$ \\
\hline & & & & Stress levels & -0.519 & 0.110 & -4.720 & $<0.001 * * *$ \\
\hline \multirow{4}{*}{3} & \multirow{4}{*}{0.531} & \multirow{4}{*}{0.282} & \multirow{4}{*}{$<0.001 * * *$} & (Constant) & 3.696 & 0.597 & 6.193 & $<0.001 * * *$ \\
\hline & & & & Motivation to study medicine & 1.226 & 0.172 & 7.117 & $<0.001 * * *$ \\
\hline & & & & Stress levels & -0.510 & 0.107 & -4.763 & $<0.001 * * *$ \\
\hline & & & & Content satisfaction & 0.129 & 0.031 & 4.140 & $<0.001 * * *$ \\
\hline \multirow{5}{*}{4} & \multirow{5}{*}{0.560} & \multirow{5}{*}{0.314} & \multirow{5}{*}{$<0.001 * * *$} & (Constant) & 1.985 & 0.691 & 2.873 & $0.004 * *$ \\
\hline & & & & Motivation to study medicine & 1.111 & 0.168 & 6.619 & $<0.001 * * *$ \\
\hline & & & & Stress levels & -0.468 & 0.104 & -4.495 & $<0.001 * * *$ \\
\hline & & & & Content satisfaction & 0.127 & 0.028 & 4.510 & $<0.001 * * *$ \\
\hline & & & & $\begin{array}{l}\text { Percentage of achievement of } \\
\text { study targets }\end{array}$ & 0.026 & 0.007 & 3.881 & $<0.001 * * *$ \\
\hline \multirow{6}{*}{5} & \multirow{6}{*}{0.567} & \multirow{6}{*}{0.321} & \multirow{6}{*}{$<0.001 * * *$} & (Constant) & 2.298 & 0.710 & 3.236 & $0.001 * *$ \\
\hline & & & & Motivation to study medicine & 1.093 & 0.167 & 6.531 & $<0.001 * * *$ \\
\hline & & & & Stress levels & -0.500 & 0.105 & -4.753 & $<0.001 * * *$ \\
\hline & & & & Content satisfaction & 0.127 & 0.028 & 4.545 & $<0.001 * * *$ \\
\hline & & & & $\begin{array}{l}\text { Percentage of achievement of } \\
\text { study targets }\end{array}$ & 0.026 & 0.007 & 3.857 & $<0.001 * * *$ \\
\hline & & & & Times of party per month & -0.039 & 0.022 & -1.789 & 0.075 \\
\hline \multicolumn{9}{|c|}{ Students of the 2019 class in the second preclinical year } \\
\hline \multirow{2}{*}{1} & \multirow{2}{*}{0.306} & \multirow{2}{*}{0.094} & \multirow{2}{*}{$<0.001 * * *$} & (Constant) & 3.800 & 0.550 & 6.905 & $<0.001 * * *$ \\
\hline & & & & Motivation to study medicine & 0.420 & 0.083 & 5.058 & $<0.001 * * *$ \\
\hline \multirow{3}{*}{2} & \multirow{3}{*}{0.363} & \multirow{3}{*}{0.131} & \multirow{3}{*}{$<0.001 * * *$} & (Constant) & 1.934 & 0.786 & 2.460 & $0.015^{*}$ \\
\hline & & & & Motivation to study medicine & 0.355 & 0.084 & 4.232 & $<0.001 * * *$ \\
\hline & & & & $\begin{array}{l}\text { Satisfaction of teaching } \\
\text { motivating desire to learn }\end{array}$ & 0.883 & 0.271 & 3.265 & $0.001 * *$ \\
\hline
\end{tabular}




\begin{tabular}{|c|c|c|c|c|c|c|c|c|}
\hline \multirow{4}{*}{3} & \multirow{4}{*}{0.402} & \multirow{4}{*}{0.162} & \multirow{4}{*}{$<0.001^{* * *}$} & (Constant) & 2.450 & 0.793 & 3.089 & $0.002 * *$ \\
\hline & & & & Motivation to study medicine & 0.330 & 0.083 & 3.978 & $<0.001 * * *$ \\
\hline & & & & $\begin{array}{l}\text { Satisfaction of teaching } \\
\text { motivating desire to learn }\end{array}$ & 0.890 & 0.266 & 3.343 & $0.001 * *$ \\
\hline & & & & $\begin{array}{l}\text { Time spent on extracurricular } \\
\text { activities (hours/week) }\end{array}$ & -0.053 & 0.018 & -2.974 & $0.003 * *$ \\
\hline \multirow{5}{*}{4} & \multirow{5}{*}{0.429} & \multirow{5}{*}{0.184} & \multirow{5}{*}{$<0.001 * * *$} & (Constant) & 3.949 & 0.975 & 4.051 & $<0.001 * * *$ \\
\hline & & & & Motivation to study medicine & 0.296 & 0.083 & 3.566 & $<0.001 * * *$ \\
\hline & & & & $\begin{array}{l}\text { Satisfaction of teaching } \\
\text { motivating desire to learn }\end{array}$ & 0.893 & 0.263 & 3.390 & $0.001 * *$ \\
\hline & & & & $\begin{array}{l}\text { Time spent on extracurricular } \\
\text { activities (hours/week) }\end{array}$ & -0.052 & 0.018 & -2.936 & $0.004 * *$ \\
\hline & & & & Stress levels & -0.434 & 0.168 & -2.587 & $0.010^{*}$ \\
\hline \multicolumn{9}{|c|}{ Students of the 2018 class in the second preclinical year } \\
\hline \multirow{2}{*}{1} & \multirow{2}{*}{0.447} & \multirow{2}{*}{0.200} & \multirow{2}{*}{$<0.001 * * *$} & (Constant) & 3.461 & 0.434 & 7.969 & $<0.001 * * *$ \\
\hline & & & & Satisfaction of study outcomes & 0.482 & 0.062 & 7.767 & $<0.001 * * *$ \\
\hline \multirow{3}{*}{2} & \multirow{3}{*}{0.521} & \multirow{3}{*}{0.272} & \multirow{3}{*}{$<0.001^{* * *}$} & (Constant) & 5.614 & 0.605 & 9.278 & $<0.001 * * *$ \\
\hline & & & & Satisfaction of study outcomes & 0.419 & 0.061 & 6.905 & $<0.001 * * *$ \\
\hline & & & & Stress levels & -0.566 & 0.116 & -4.891 & $<0.001 * * *$ \\
\hline \multirow{4}{*}{3} & \multirow{4}{*}{0.545} & \multirow{4}{*}{0.297} & \multirow{4}{*}{$<0.001 * * *$} & (Constant) & 4.312 & 0.746 & 5.784 & $<0.001 * * *$ \\
\hline & & & & Satisfaction of study outcomes & 0.389 & 0.061 & 6.425 & $<0.001 * * *$ \\
\hline & & & & Stress levels & -0.554 & 0.114 & -4.856 & $<0.001 * * *$ \\
\hline & & & & Motivation to study medicine & 0.555 & 0.191 & 2.906 & $0.004 * *$ \\
\hline \multirow{5}{*}{4} & \multirow{5}{*}{0.560} & \multirow{5}{*}{0.314} & \multirow{5}{*}{$<0.001 * * *$} & (Constant) & 7.654 & 1.556 & 4.919 & $<0.001 * * *$ \\
\hline & & & & Satisfaction of study outcomes & 0.394 & 0.060 & 6.562 & $<0.001 * * *$ \\
\hline & & & & Stress levels & -0.519 & 0.114 & -4.560 & $<0.001 * * *$ \\
\hline & & & & Motivation to study medicine & 0.575 & 0.189 & 3.037 & $0.003 * *$ \\
\hline & & & & Sleep time (o'clock) & -0.144 & 0.059 & -2.440 & $0.015 *$ \\
\hline \multirow{6}{*}{5} & \multirow{6}{*}{0.557} & \multirow{6}{*}{0.310} & \multirow{6}{*}{$<0.001 * * *$} & (Constant) & 6.760 & 1.387 & 4.875 & $<0.001 * * *$ \\
\hline & & & & Satisfaction of study outcomes & 0.602 & 0.178 & 3.377 & $0.001 * *$ \\
\hline & & & & Stress levels & -0.517 & 0.106 & -4.856 & $<0.001 * * *$ \\
\hline & & & & Motivation to study medicine & 0.358 & 0.056 & 6.350 & $<0.001 * * *$ \\
\hline & & & & Sleep time (o'clock) & -0.120 & 0.049 & -2.459 & $0.015 *$ \\
\hline & & & & $\begin{array}{l}\text { Number of days having breakfast } \\
\text { (day (s)/week) }\end{array}$ & 0.073 & 0.035 & 2.107 & $0.036^{*}$ \\
\hline
\end{tabular}

$* \mathrm{p}<0.05, * * \mathrm{p}<0.01, * * * \mathrm{p}<0.001$.

\section{Discussion}

This study determined factors that affected happiness of preclinical students focusing on aspects of teaching and learning, study habits, and academic achievement. Most previous studies examined the influence of general lifestyle factors on happiness including age, marital status, exercise, emotion intelligence, physical and mental health, and family relationship (Alshehri et al., 2016; Bahrami et al., 2011; Sahraian et al., 2012; Sasanpour et al, 2012; Wongratanacheewin et al., 2015); however, only few reported its association with academic achievement (Wongratanacheewin et al., 2015). To the best of our knowledge, this is the first study that examined the influence of factors in aspects of teaching and learning on students' happiness. Firstly, we explored the top ten ranking factors that increased the students' happiness with open-ended questions. In the students of the 2018 and 2019 classes, the common top 5 ranking factors increasing their happiness were teaching of instructors, content satisfaction, content understanding, free time, and handouts.

From correlation analysis, by close-ended questions, happiness of the students in 2 preclinical years in both classes was positively correlated with happiness in learning subjects taught in a particular year; satisfaction of content, study outcomes, materials, handouts, teaching motivating desire to learn, and applicability of content to medical profession; and the percentage of achievement of study targets. The results, obtained from both open- and closeended questions suggested that teaching and learning factors had a major impact on student's happiness. So, effective teaching and learning environments should be encouraged to increase students' happiness. Furthermore, 
educational faculty development programs should be promoted to empower faculty members in enhancement of effective teaching and learning.

In both classes, approximately two-third of the students had high motivation, one-third had medium motivation, and only few of them $(<5 \%)$ had low motivation to study medicine as reported in the previous study (Raksadawan, Sitticharoon, Charoenngam, Maikaew, \& Keadkraichaiwat, 2020). Interestingly, students with high motivation had highest happiness, followed by those with medium and low motivation, respectively especially in preclinical years. From correlation analyses, happiness of students in both classes had positive correlations with motivation to study medicine. From multiple linear regression analysis, motivation to study medicine provided a contribution to happiness of students in both classes. These results indicate that happiness in preclinical students was related to motivation to study medicine. Our results were consistent with a previous study revealing that self-desire to study medicine is one factor determining students' happiness (Wongratanacheewin et al., 2015). Therefore, motivation to study medicine should be promoted among students to help maintain their happiness during preclinical years. Furthermore, this factor might be included in the criteria for enrollment of medical students. For the procedure of medical school admittance of our institution, there were multiple choice questions (MCQ) examination in topics including physics, chemistry, biology, mathematics, English, blinded for peer review, and social sciences, physical examination, medical aptitude test, and interview. Unfortunately, we did not have any processes to differentiate between motivated and non-motivated students. In the future, we have a plan to establish the multiple mini interview in the enrollment process to determine factors that are necessary for being a good medical doctor including motivation to be a medical profession rather than only the MCQ scores.

For the association between study habits and students' happiness, the 2018/2 students who spent more time on internet for non-academic use ( $\geq 3$ hours/day) had less happiness than students who spent less time ( $<3$ hours/day). This might be because those with low happiness tended to use more internet for non-academic purpose to increase their happiness.

The 2019/2 students who had very low happiness had significantly higher significantly time spent on lesson review and recorded-e-lecture study than other groups of students. In addition, happiness of the 2019/1 and 2018/2 students had negative correlations with the percentage of time spent on recorded-e-lecture study per class. This might be because students who spent higher amount of time on lesson review and recorded-e-lecture study probably had less free time, one of the top ten ranking factors increasing students' happiness, leading to less happiness.

For academic performance, the 2018/2 students with higher happiness had higher GPA of a certain academic year; and the 2019/1 and 2018/2 students with higher happiness had higher expected score and the percentage of achievement of study targets. From correlation analysis, happiness of students had positive correlations with GPA of a certain academic year and expected score in the 2019/1 and 2018/2 classes; and had positive correlations with the percentage of achievement of study targets in all classes. These results suggest that higher happiness students had higher academic performance. Our results were in accordance with a previous study showing that academic achievement was one of factors predicting happiness of students (Wongratanacheewin et al., 2015). In all classes, students with very low happiness had higher instances of lateness to class and absence from class/year. Furthermore, in both classes, approximately $50 \%$ of the students had medium stress levels, approximately $30 \%$ of them had high to very high stress levels, and approximately $20 \%$ of them had low to very low stress levels as reported in the previous study (Raksadawan et al., 2020). Happiness of the 2018/2 students had a negative correlation with instances of lateness to class and absence from class/year. Furthermore, students who had lower happiness had higher stress levels and happiness of students had negative correlations with stress levels in all classes. Collectively, students with low happiness had lower academic performance, higher stress level, and less class attendance. As a result, academic achievement and class attendance might be used as monitoring tools to determine happiness of students.

\section{Conclusions}

Factors related to increased happiness in preclinical students were teaching and learning factors including teaching of instructors, content satisfaction and understanding, handout, free time, and academic achievement. Furthermore, students' attitude and study habits including high levels of motivation to study medicine, expected score, and the percentage of achievement of study targets; less amount of time spent on recorded-e-lecture study and internet for non-academic use; and low stress levels were associated with higher happiness of students. Class attendance and academic achievement might be used as tools to monitor students' happiness during preclinical years. Effective teaching and learning environments; activities increasing students' motivation; and good students' attitude and study habits should be promoted to maintain or enhance happiness of students during preclinical studies. 


\section{Recommendations for Further Studies}

Further studies on determining students' happiness after improvement of teaching and learning environments, augmenting activities that enhance students' motivation, and promoting good study habits among medical students, are required to prove whether enhancement of these factors could effectively increase students' happiness.

\section{Ethics Approval}

The study protocol was approved by the Siriraj Institutional Review Board (COA no. Si 022/2015). Written inform consents were obtained by all participants.

\section{References}

Aktekin, M., Karaman, T., Senol, Y. Y., Erdem, S., Erengin, H., \& Akaydin, M. (2001). Anxiety, depression and stressful life events among medical students: a prospective study in Antalya, Turkey. Medical Education, 35(1), 12-17. https://doi.org/10.1046/j.1365-2923.2001.00726.x

Alshehri, A. A., Althobaiti, S. M., Alsaadi, H. D., Alnemari, A. K., Alyami, H., Alyami, M., \& Alswat, K. A. (2016). Subjective Happiness Assessment among Taif University Medical Students. American Journal of Educational Research, 4(1), 111-114. https://doi.org/10.12691/education-4-1-17

Bahrami, S., Rajaeepour, S., Rizi, H. A., Zahmatkesh, M., \& Nematolahi, Z. (2011). The relationship between students' study habits, happiness and depression. Iranian Journal of Nursing and Midwifery Research, 16(3), 217-221.

Eva, E. O., Islam, M. Z., Mosaddek, A. S., Rahman, M. F., Rozario, R. J., Iftekhar, A. F., Ahmed, T. S., Jahan, I., Abubakar, A. R., Dali, W. P., Razzaque, M. S., Habib, R. B., \& Haque, M. (2015). Prevalence of stress among medical students: a comparative study between public and private medical schools in Bangladesh. BMC Research Notes, 8, 327. https://doi.org/10.1186/s13104-015-1295-5

Kjeldstadli, K., Tyssen, R., Finset, A., Hem, E., Gude, T., Gronvold, N. T., Ekeberg, O., \& Vaglum, P. (2006). Life satisfaction and resilience in medical school - a six-year longitudinal, nationwide and comparative study. BMC Medical Education, 6(1), 1-8. https://doi.org/10.1186/1472-6920-6-48

Rabito-Alcon, M. F., \& Rodriguez-Molina, J. M. (2016). Satisfaction with life and psychological well-being in people with gender dysphoria. Actas Espanolas de Psiquiatria, 44(2), 47-54.

Rahman, N. I. A. R., Ismali, S., Seman, T. N. A. B. T., Rosli, N. F. A. B., Jusoh, S. A. B. M., Dali, W. P. E. W., Islam, M. Z., \& Haque, M. (2013). Stress Among Preclinical Medical Students of University Sultan Zainal Abidin. Journal of Applied Pharmaceutical Science, 3(11), 6. https://doi.org/10.7324/JAPS.2013.31113

Raksadawan, Y., Sitticharoon, C., Charoenngam, N., Maikaew, P., \& Keadkraichaiwat, I. (2020). Factors Influencing Academic Achievement in Preclinical Students. International Educational Research, 3(3), 8-21. https://doi.org/10.30560/ier.v3n3p8

Sahraian, A., \& Vakili, S. M. (2012). Studying the Happiness Level among Medical Students of Shiraz Medical Sciences University in 2010. Shiraz E-Medical Journal, 13(4), 179-186.

Saipanish, R. (2003). Stress among medical students in a Thai medical school. Medical Teacher, 25(5), 502-506. doi:10.1080/0142159031000136716

Sasanpour, M., Khodabakhshi, M., \& Nooryan, K. (2012). The Relationship between Emotional Intelligence, Happiness and Mental Health in Students of Medical Sciences of Isfahan University. International Journal of Collaborative Research on Internal Medicine \& Public Health, 4(9), 1614-1620.

Slavin, S. J. (2016). Medical Student Mental Health: Culture, Environment, and the Need for Change. The Journal of the American Medical Association, 316(21), 2195-2196. https://doi.org/10.1001/jama.2016.16396

Wongratanacheewin, J., Vimonvanich, S., Teeratakulpisarn, N., Srimanta, N., Pooparadorn, L., Choorus, B., Chitkulsampan, O., Paileeklee, S., \& Srisaenpang, S. (2015). The Level of Happiness and Possibly Related Factors among Medical Students of Khon Kaen University 2015. Srinagarind Medical Journal, 30(7), 56.

\section{Copyrights}

Copyright for this article is retained by the author(s), with first publication rights granted to the journal.

This is an open-access article distributed under the terms and conditions of the Creative Commons Attribution license (http://creativecommons.org/licenses/by/4.0/). 